\title{
Tratamento de dejetos suínos: oportunidades de conversão em energia
}

\author{
RESUMO
}

Leandro Gasparello de Oliveira leandro.gasparello@gmail.com Universidade Tecnológica Federal do Paraná (UTFPR), Ponta Grossa, Paraná, Brasil

\section{Jovani Taveira de Souza} jovanisouza5@gmail.com Universidade Tecnológica Federal do Paraná (UTFPR), Ponta Grossa, Paraná, Brasil

\section{Antonio Carlos de Francisco}

acfrancisco@utfpr.edu.br
Universidade Tecnológica Federal do

Paraná (UTFPR), Ponta Grossa, Paraná,

Brasil
O presente artigo se propõe a revisar o tema de gerenciamento de dejetos suínos, em especial no que tange à conversão destes resíduos em biogás e energia, de forma a minimizar os impactos ambientais causados pela prática da suinocultura. $\mathrm{Na}$ contextualização geral é abordada a representatividade da cadeia produtiva no Brasil e no cenário internacional, além dos resíduos provenientes da pecuária. O enfoque é dado à geração de biogás, biofertilizantes e energia. Dessa forma, a revisão de literatura elenca os estudos correlacionados com a temática e suas contribuições para a área. Neste sentido se estabelece como objetivo revisar artigos dos principais autores internacionais e nacionais sobre o tema nos últimos cinco anos, no sentido de destacar aqueles de maior relevância para a pesquisa. Como resultado verificou-se através da pesquisa bibliográfica que o tratamento de dejetos suínos se torna cada vez mais uma necessidade em função dos seus impactos ambientais e da capacidade de conservação limitada do solo, do ar e da água, tendo em vista as demandas do setor no cenário atual.

PALAVRAS-CHAVE: Dejetos suínos. Resíduos. Geração de Biogás. 


\section{INTRODUÇÃO}

O Brasil é o quarto maior produtor de carne suína no mundo. Isso representa o equivalente a 3,7 milhões de toneladas de suínos (EMPRAPA, 2017). O principal problema desta atividade, portanto, é a geração de enormes quantidades de dejetos que podem corroborar para a poluição dos ecossistemas terrestres e aquáticos (SEGAT et al., 2015).

A produção intensiva de suínos está centralizada na região sul do Brasil, principalmente em propriedades familiares em sistema de integração basicamente, conforme registrado por Buhring e Silveira (2016), que fizeram cálculos da quantidade de dejetos e de produção de biogás, além de redução de emissões de metano. O estudo comprova que $67 \%$ do plantel da região mencionada possui potencial elevado de produção de biogás e de redução de emissão de metano pela adoção do tratamento dos dejetos de suínos através da digestão anaeróbia, com possibilidade de transformar um passivo ambiental em ativo energético e econômico na propriedade rural.

Uma das alternativas para o tratamento dos dejetos de suínos concerne à digestão anaeróbia, que corresponde ao processo de decomposição da matéria orgânica entre bactérias. Outra possibilidade é o processo de compostagem que compreende em decompor o estrume suíno, transformando-os em biofertilizantes, utilizado na agricultura como adubo orgânico. Com isso, reduz-se significativamente a emissão de gases poluentes na atmosfera, bem como a redução de impactos nocivos ao meio ambiente.

Nesse processo, enfatiza-se a necessidade da busca por caminhos mais limpos e sustentáveis de produção e consumo baseados nos conceitos da ecologia agroindustrial. Essa estratégia integradora dos processos industriais e sua inserção no ecossistema devem impulsionar o setor produtivo de forma a prepará-lo para competir também no cenário internacional.

Com isso, objetiva-se com esse estudo, revisar o tema de gerenciamento de dejetos suínos, no que se refere à conversão destes resíduos em biogás e energia.

Para este fim, o trabalho foi estruturado com os conceitos fundamentais envolvendo gestão dos dejetos, biogás e geração de energia e tipos de biodigestores. Após, foi relatado os procedimentos metodológicos adotados, seguido dos resultados e, por fim, a conclusão do estudo.

\section{GESTÃO DOS DEJETOS}

Uma grande variedade de estudos desvenda os mecanismos e processos envolvidos na gestão dos dejetos da produção animal, os quais indicam possíveis efeitos benéficos de mudanças nas práticas de gestão (CHADWICK et al., 2011).

Andrade (2014) assegura que em estudos recentes, pesquisadores tentaram identificar, estimar e especificar as emissões de gases de efeito estufa (GEE) e o uso de dejetos animais nas escalas regional e global (LESSCHEN et al., 2011; MACDONALD et al., 2011), mas diversas suposições tiveram de ser feitas para contornar a falta de informações mais detalhadas. 
Os dejetos em diversos casos são destinados diretamente no solo, em rios e lagoas, sem o devido tratamento, pelo fato da sua disposição ser relativamente simples e ter baixo custo.

O tratamento dos dejetos deve ser analisado sob as seguintes perspectivas, segundo Araújo, Montenegro e Maranguape (2016):

a) Preservacionista: Eliminar ou amenizar o elevado volume de dejetos gerado nas propriedades;

b) Agronômica: Utilizar os dejetos como fertilizante disponível nas propriedades;

c) Sanitária: Promover o tratamento adequado dos dejetos.

A digestão anaeróbia é constituída por quatro etapas sendo a primeira fase, a Hidrólise, na qual corresponde à decomposição de compostos orgânicos, tais como proteínas, gorduras e carboidratos em aminoácidos, ácidos graxos e açúcares (ROHSTOFEE, 2010). Já na segunda etapa, conhecida como Acidogênese, as bactérias têm o papel de transformar os compostos advindos da primeira fase em ácidos gordos voláteis e/ou ainda em outros ácidos orgânicos (FRITSCH; HARTMEIER; CHANG, 2008).

$\mathrm{Na}$ terceira fase, denominada de Acetogênese, as bactérias transformam os ácidos gerados na terceira fase em dióxido de carbono e acetato (ZHENG et al., 2009). Por fim, a última etapa do processo é a Metanogênese que compreende em converter o acetato e o dióxido de carbono em metano, surgindo então o biogás (CARNEIRO, 2013).

Outra possibilidade de tratamento adequado para os dejetos é a compostagem que compreende no processo de decomposição biológica de resíduos orgânicos, a partir de uma população diversificada de microrganismos, em condições adequadas de temperatura, umidade e aerobiose e que, após as etapas de degradação e maturação, fornece um produto estável e rico em matéria orgânica (ABNT, 1996). O produto principal de compostagem é o fertilizante ou adubo orgânico.

\section{BIOGÁS E GERAÇÃO DE ENERGIA}

O biogás é uma mistura gasosa composta principalmente por gás carbônico $\left(\mathrm{CO}_{2}\right)$ e metano $\left(\mathrm{CH}_{4}\right)$ originado por um processo biológico de decomposição da matéria orgânica por meio de digestão anaeróbia (FRIEHE, WEILAND e SCHATTAUER, 2010). Segundo Weiland (2009), a produção de biogás através de digestão anaeróbia oferece significativas vantagens sobre outras formas de produção de bioenergia. A geração de energia através do biogás reduz drasticamente a emissão de GEE - comparada aos combustíveis fósseis - utilizando recursos disponíveis localmente. Além disso, a queima do combustível transforma o metano em dióxido de carbono, o qual é 23 vezes menos poluente em termos de impacto sobre as mudanças climáticas.

Antonelli (2013) assegura que o uso do resíduo de suinocultura para geração de energia elétrica, térmica e de biofertilizante é uma forma promissora, de 
gerenciamento do resíduo que contribui para a redução da contaminação de corpos de água e preservação do ecossistema. A biodigestão é uma tecnologia de conversão da biomassa presente no resíduo em um biocombustível gasoso de médio poder calorífico. $O$ gás pode ser utilizado em motor ciclo Otto, para geração de energia elétrica, na propriedade geradora do resíduo (ANTONELLI, 2013).

Antonelli (2013) avaliou a capacidade de produção de biogás, com os resíduos de suinocultura, estimando a produção de energia elétrica e a área necessária para aplicar o biofertilizante produzido. Para realizar o estudo foi feito um levantamento bibliográfico, sobre resíduos de suinocultura, suas características, e o processo de biodigestão anaeróbio, com isso foi possível estimar a produção de resíduo gerado por cada suíno, a produção de biogás e a geração de energia elétrica. Foi realizado uma caracterização do município de Missal e um levantamento da capacidade produtora de suínos, sendo determinado que seria possível produzir $20 \%$ da energia elétrica consumida nas áreas rurais do município e aplicar biofertilizante em $67 \%$ da área destinada para lavoura.

Entre as energias renováveis, o biogás tem o potencial para ser integrado na economia rural, uma vez que utiliza recursos renováveis. Com a produção do biogás em áreas rurais, a paisagem agrícola e também práticas agrícolas são transformadas, exigindo novas formas de organizar processos de produção de energia (BLUEMLING et al., 2013).

Ainda segundo Bluemling et al. (2013), a produção de biogás rural difere de outras fontes de energia renováveis na medida em que está incorporado no setor agrícola e estão relacionadas estruturas institucionais e políticas. Em oposição a outras fontes de energia renováveis, a produção não depende apenas da matéria prima (material orgânico), mas das estruturas institucionais e do envolvimento dos agricultores para tornar a energia disponível.

Além de reduzir a poluição a padrões ambientalmente toleráveis, é recomendável que os processos de tratamento agreguem valor ao resíduo final, tornando-o autossustentável. De acordo com Oliveira e Nunes (2006) o adubo orgânico (biofertilizante), a energia térmica ou elétrica são fontes alternativas desses resíduos.

Para Oliveira Júnior (2013), as grandes transformações dos sistemas de produção de animais confinados têm trazido avanços importantes ao setor, sendo que os problemas ambientais são resultado da concentração e aumento de escala da atividade. Isso cria a necessidade de procura de novas opções para mitigar o problema e também agregar valor aos resíduos gerados.

A geração e o aproveitamento do biogás a partir desses resíduos se mostram como uma opção interessante, pois permite o aproveitamento do biogás produzido nas propriedades rurais como fonte de energia térmica e elétrica, reduzindo os custos derivados da demanda energética.

A enorme quantidade de dejetos suínos gerada e a falta de processos sustentáveis na criação de suínos podem ser considerados como os principais problemas ambientais dessa atividade. Com isso deve-se conhecer também, os impactos negativos ocasionados pelos processos inadequados de disposição desses resíduos, como o despejo em rios e riachos ou até mesmo por tecnologias de tratamentos ineficientes, causando poluição e riscos sanitários (OLIVEIRA JÚNIOR, 2013). 


\section{TIPOS DE BIODIGESTORES}

Os biodigestores são estruturas que tem como objetivo facilitar a biodigestão anaeróbia (RICARDO, 2013; SILVA, 2017). A partir dos mesmos é possível a formação e captação do gás metano. No sistema biodigestor, o processo dos micro-organismos na oxidação da matéria produz gases; esses gases podem ser usados na queima, produzindo energia. Com isso, o metano não será emitido para a atmosfera (CAVALCANTI, 2011).

Existem alguns modelos de biodigestores, os quais podemos destacar: o modelo chinês e indiano, o alemão e o canadense.

O modelo chinês é formado pelos seguintes componentes: caixa de carga, tubo de carga, câmara de biodigestão cilíndrica com fundo esférico, gasômetro em formato esférico, galeria de descarga e caixa de descarga (LUCAS JUNIOR; SOUZA, 2009). A Figura 1 ilustra este tipo de biodigestor.

Figura 1 - Biodigestor chinês

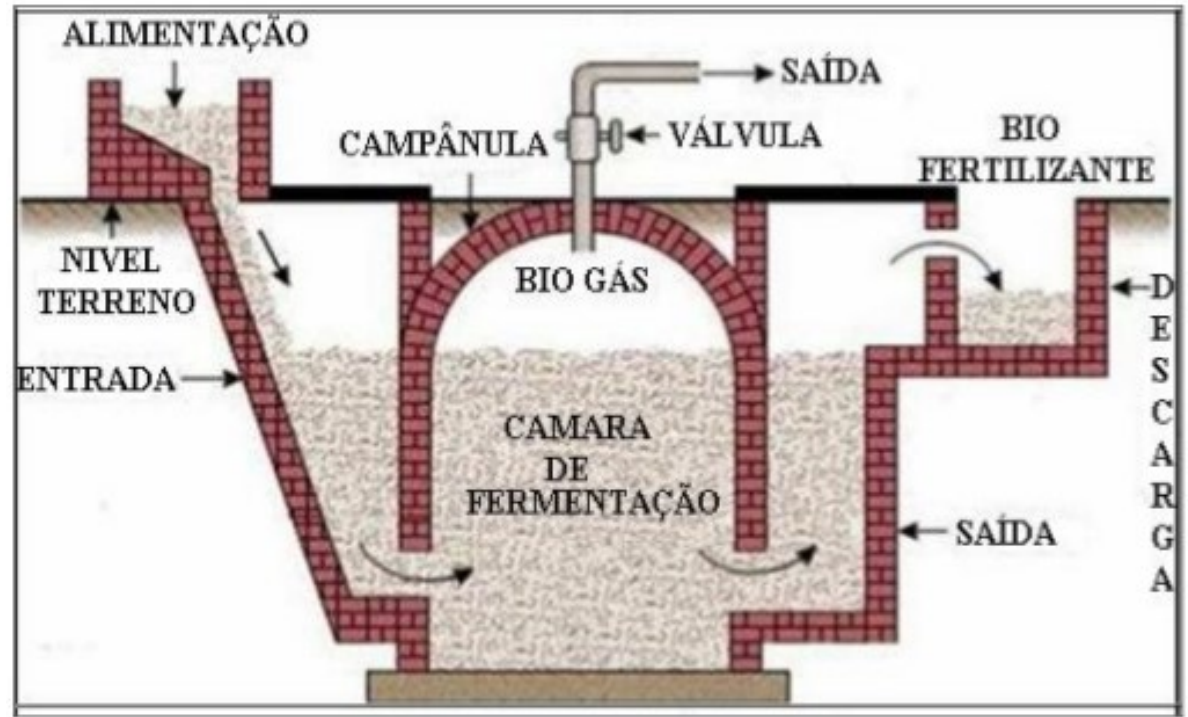

Fonte: Fonseca, Araújo e Hendges (2009).

O biodigestor chinês é construído exclusivamente de alvenaria, sem necessitar o uso de gasômetro com chapa de aço e, por isso, pode ser facilitado o vazamento de biogás quando a construção é feita de maneira inadequada (DEGANUTTI et al., 2002). O biodigestor é formado basicamente em duas partes: a primeira por um tanque que acolhe e conduz a digestão da biomassa, e o segundo, pela campânula, que mantém o biogás (MARTELLI et al., 2011).

Em relação ao biodigestor indiano, pode-se afirmar que é mais sofisticado do que o chinês, pois a Índia, procurou desenvolver o biodigestor para suprir o déficit energético do país, enquanto que a China, foi devido a busca por fertilizantes para produção de alimentos para a população (COLDEBELLA et al., 2006).

O biodigestor indiano tem como característica o uso de uma campânula flutuante como gasômetro (NEVES, 2010). Os principais componentes para esse tipo de biodigestor, segundo Lucas Junior e Souza (2009) são: caixa de carga; tubo de carga; câmara de biodigestão cilíndrica; gasômetro; tubo-guia; tubo de 
descarga; caixa ou canaleta de descarga. A Figura 2 é um exemplo do biodigestor indiano.

Figura 2 - Biodigestor indiano

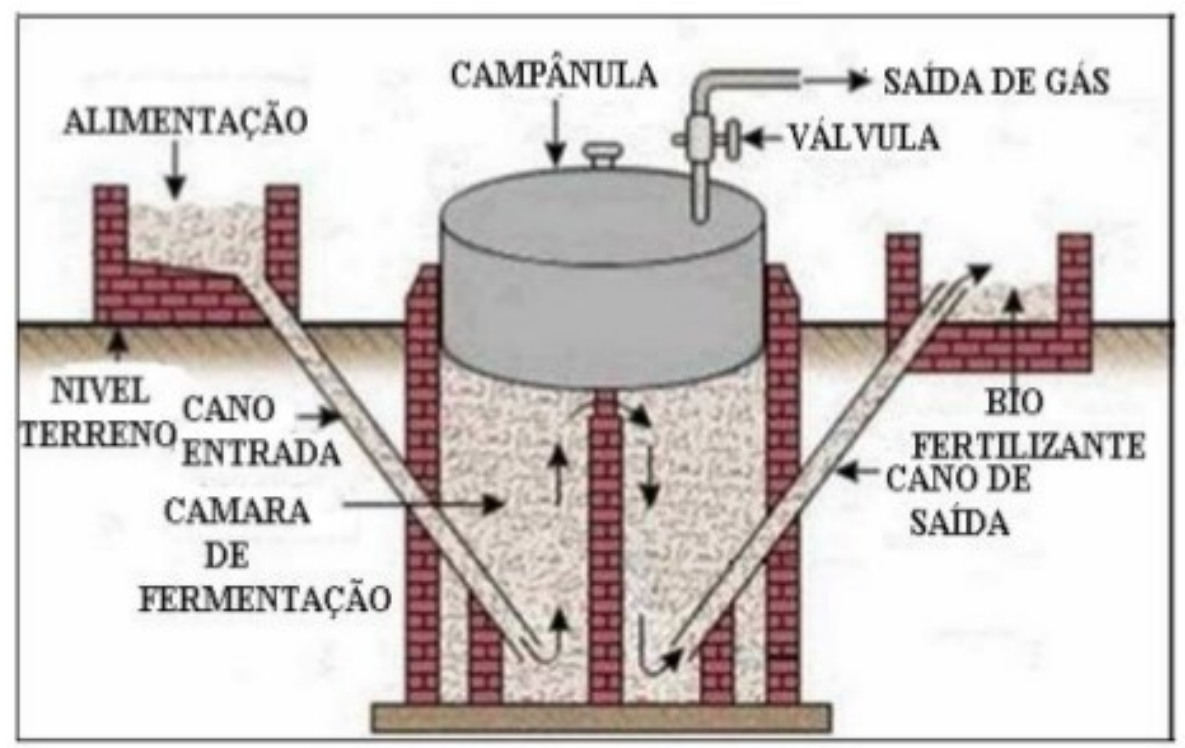

Fonte: Fonseca, Araújo e Hendges (2009).

Neste tipo de biodigestor os abastecimentos e esvaziamento são feitos de maneira periódica, sendo assim é mais difícil o isolamento. Com isso, ocorrem perdas de calor pela câmara de gás metálica. Não é indicado para regiões com climas frios (GASPAR, 2003).

A Figura 3 ilustra o biodigestor alemão. Para Silva (2017) a Alemanha investiu fortemente no desenvolvimento de biotecnologia para o setor de biodigestão anaeróbica, e atualmente apresenta tecnologia avançada para construir sistemas eficientes.

Figura 3 - Biodigestor Alemão

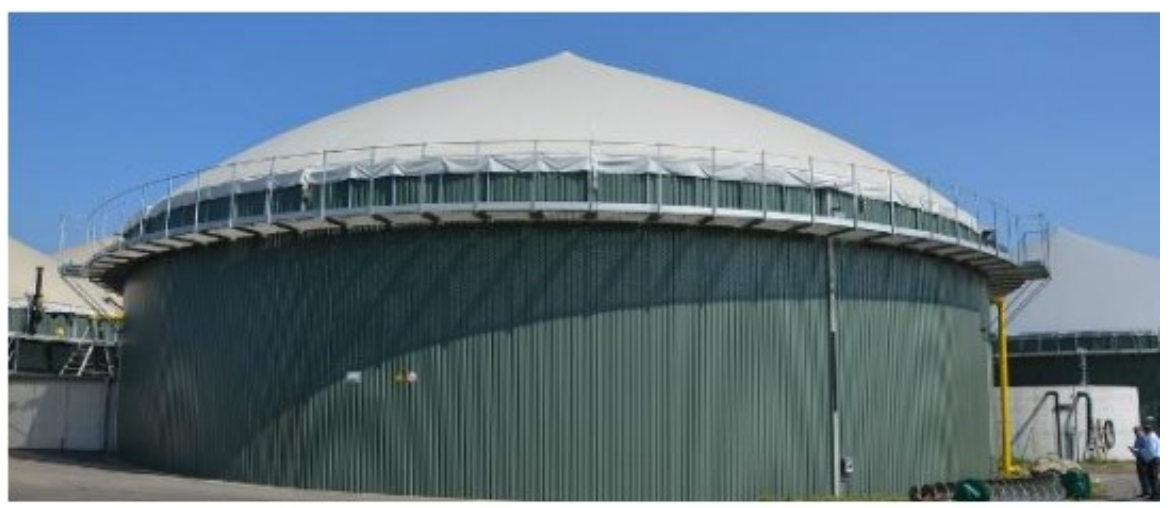

Fonte: Machado (2015).

A construção de um biodigestor de tecnologia Alemã é construída sobre o solo, no formato redondo. Neste biodigestor, há um processo fortemente controlável e estável, tendo agitadores que apresentam uma boa mistura e produção contínua de gás (SILVA, 2017). 
Por fim, o biodigestor canadense (Figura 4) também conhecido como biodigestor de fluxo tubular. Tem como formato uma construção horizontal com câmara de biodigestão escavada no solo, contendo gasômetro inflável (LUCAS JUNIOR; SOUZA, 2009). O biodigestor de fluxo tubular é bem utilizado em propriedades rurais. Uma das características do mesmo é que o biogás pode ser enviado para um gasômetro separado, permitindo assim um maior controle sobre o biogás (NEVES, 2010).

Figura 4 - Biodigestor canadense

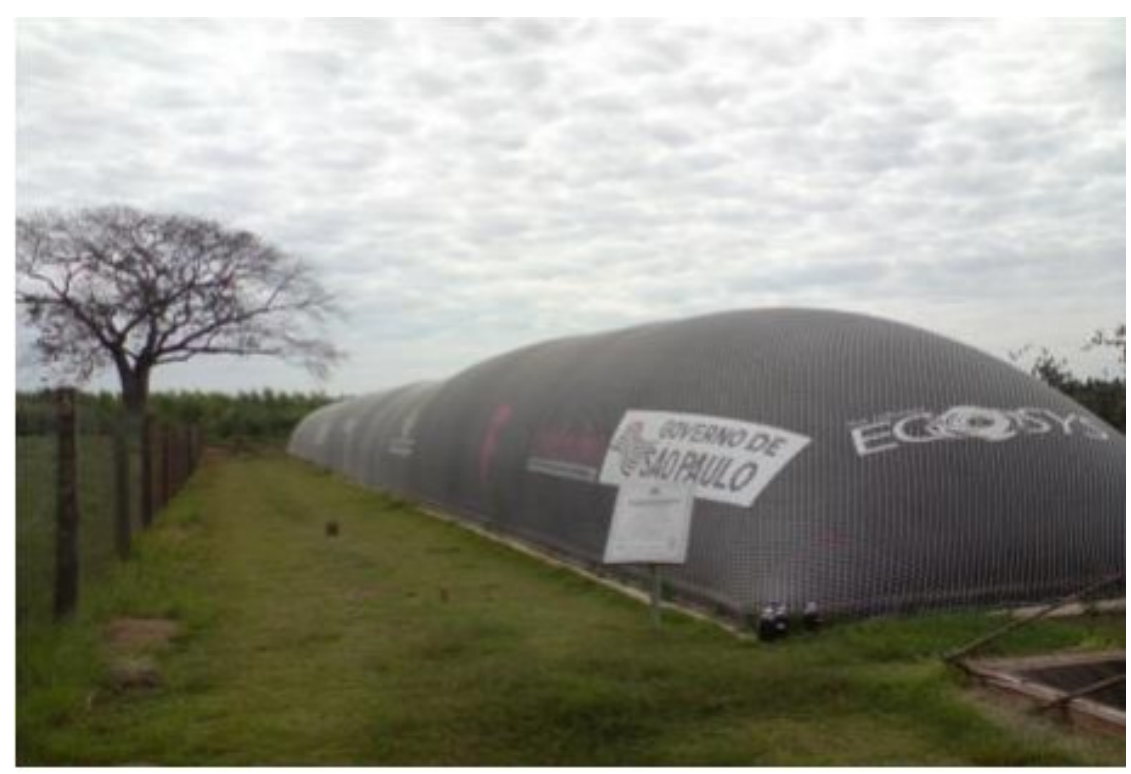

Fonte: Martelli (2011).

A partir das descrições dos biodigestores, serão apresentados nas próximas seções: a metodologia, resultados e conclusão do estudo.

\section{MATERIAIS E MÉTODOS}

Esta pesquisa envolve levantamento bibliográfico, a partir de estudos publicados, mais recentes, envolvendo artigos publicados internacionalmente e nacionalmente.

As palavras utilizadas para encontrar os artigos relacionados com a temática foram "produção de suínos", "gerenciamento da produção de suínos" e "geração de energia a partir de dejetos suínos". O software para gerenciamento das referências e remoção de artigos duplicados foi o EndNote versão X6 (ENDNOTE, 2017).

Os critérios de inclusão do estudo foram informações que pudessem ser relevantes para a pesquisa. Já os critérios de exclusão do estudo foram publicações sem data, textos não científicos e que privilegiassem uma simples opinião sobre o tema.

Inicialmente, foi realizado uma revisão de literatura de todos os títulos e resumos, a fim de assegurar o tema da pesquisa. Posteriormente, com os artigos definidos, analisou-se a leitura dos textos na íntegra. 
A seguir, serão evidenciados os resultados encontrados no presente estudo.

\section{RESULTADOS E DISCUSSÃO}

Nesta seção, serão apresentados os resultados obtidos a partir do levantamento realizado a partir da literatura.

A suinocultura requer um programa de controle de dejetos suínos, para sua correta utilização, o que implica considerar cinco etapas: produção, coleta, armazenagem, tratamento, distribuição e utilização dos dejetos (na forma sólida, líquida ou pastosa) (LIMA, 2015). O tratamento para cumprir seu objetivo final e ser efetivo, necessitará converter os dejetos suínos em material inofensivo ao manuseio e ao meio ambiente (ABCS, 2011).

Segundo os levantamentos feitos, as abordagens encontradas na literatura mostram que é grande a ausência de programas voltados para o gerenciamento e tratamento dos dejetos suínos, de modo que os problemas na esfera ambiental possam ser minimizados agregando valor ao produto final.

O biodigestor modelo canadense é o mais utilizado atualmente no Brasil (FEAM, 2015). O resultado da decomposição dos dejetos é a geração de um gás de alto poder energético, capaz de substituir a lenha, a gasolina e o GLP além da valorização dos dejetos para uso agronômico.

A capacidade do biodigestor em degradar os dejetos suínos depende de vários fatores como temperatura, sólidos voláteis e atividade dos micro-organismos presentes no biodigestor, além de outros parâmetros que influenciam diretamente na produção de biogás.

\section{CONCLUSÕES}

O presente trabalho teve como objetivo revisar o tema de gerenciamento de dejetos suínos, a partir de trabalhos encontrados na literatura, a respeito da conversão destes resíduos em biogás e energia, de forma a minimizar os impactos ambientais causados pela prática da suinocultura.

Diante do estudo realizado, foi possível perceber a inexistência de um programa de sustentabilidade da suinocultura no Brasil, que integre os produtores e as agroindústrias tornando mais difícil a mudança de realidade nas propriedades.

De acordo com os levantamentos, a resolução desses problemas passa pelo estabelecimento de estratégias que integrem os componentes: formação de recursos humanos, desenvolvimento de metodologias e tecnologias e de sensibilização (educação ambiental).

Conforme o que foi levantado na revisão, o tratamento de dejetos de suínos parece cada vez mais uma necessidade em função dos seus impactos ambientais e da capacidade limitada do solo em reciclar os nutrientes nele aplicados.

O grande desafio ainda reside em transferir as tecnologias de tratamento aos suinocultores brasileiros, que muitas vezes apresentam baixa capacidade de investimento para mitigação dos problemas ambientais da atividade. 
Sugere-se para trabalhos futuros, revisar o gerenciamento de dejetos bovinos, no que se refere a coleta, tratamento, armazenagem e distribuição, além de explorar a codigestão anaeróbia envolvendo outros tipos de resíduos agroindustriais. 


\title{
Treatment of swine manure: opportunities for energy conversion
}

\begin{abstract}
The present article proposes to review the management of swine manure, especially with regard to the conversion of this waste into biogas and energy, in order to minimize the environmental impacts caused by swine practices. In the general context, the representativeness of the production chain in Brazil and in the international scenario, as well as the residues from livestock, are addressed. The focus is on the generation of biogas, biofertilizers and energy. Thus, the literature review lists the studies correlated with the theme and its contributions to the area. In this sense, it is established as objective to review articles of the main international and national authors on the subject in the last five years, in order to highlight those of greater relevance for the research. As a result, it was verified through the bibliographic research that the treatment of swine manure becomes increasingly a necessity due to its environmental impacts and the limited conservation capacity of soil, air and water, in view of the demands of the sector in the current scenario.
\end{abstract}

KEYWORDS: Swine waste. Residues. Biogas generation. 


\section{REFERÊNCIAS}

ABCS. Associação Brasileira de Criadores de Suínos. Produção de suínos: teoria e prática. Brasília, DF, 2014.

ABCS - Associação Brasileira de Criadores de Suínos; MAPA - Ministério da Agricultura, Pecuária e Abastecimento. Manual Brasileiro de Boas Práticas Agropecuárias na Produção de Suínos. Brasília, 140 p. 2011

ABNT - Associação Brasileira de Normas Técnicas. NBR 13.591: compostagem: terminologia. Rio de Janeiro, 1996.

ANDRADE, C. B. O uso de geotecnologias na gestão de dejetos da produção animal: construindo uma proposta. Florianópolis - SC, 2014. Disponível em: <https://repositorio.ufsc.br/bitstream/handle/123456789/131828/CAIO\%20BUS TANI\%20ANDRADE.pdf?sequence=1>. Acesso em 02 jul. 2017.

ANTONELLI, J. Gestão dos resíduos de suinocultura no município de Missal. 2013. 32p. Monografia (Especialização em Gestão Ambiental em Municípios). Universidade Tecnológica Federal do Paraná, Medianeira, 2013.

ARAÚJO, N. S.; MONTENEGRO, R. C.; MARANGUAPE, J. S. Uso de tecnologias no tratamento de dejetos de suínos para redução dos impactos ambientais. VII Congresso Brasileiro de Gestão Ambiental - CONGEA. Campina Grande, 2016.

BLUEMLING, B.; MOL, A. P. J.; TU, Q. The social organization of agricultural biogas production and use. Energy Policy, v. 63, p. 10-17, 2013. crossref

BUHRING, G. M. B.; SILVEIRA, V. C. P. O biogás e a produção de suínos no Sul do Brasil. Revista Brasileira de Energias Renováveis, v.5, n.2, p.222-237, 2016.

CARNEIRO, D. R. C. Viabilidade técnica e económica de uma unidade centralizada de co-digestão anaeróbia de resíduos orgânicos. Dissertação (Mestrado em Engenharia do Ambiente) - UNIVERSIDADE DO PORTO FACULDADE DE ENGENHARIA - FEUP, Portugal, 2013.

CAVALCANTI, M. Mercado de Créditos de Carbono e a Atividade Suinícola: Uma Análise de Projetos e Regiões do Brasil 2010. In: Congresso Nacional de Excelência em Gestão, 7., 2011, Niterói. Anais... Niterói: Cneg, 2011.

CHADWICK, D. et al. Manure management: implications for greenhouse gas emissions. Animal Feed Science and Technology, v.166, p.514-531, jan. 2011. 
COLDEBELLA, A. et al. Viabilidade da cogeração de energia elétrica com biogás da bonivocultura de leite. Energia no Meio Rural. 2006, Campinas. Disponível em:

$<$ http://www.proceedings.scielo.br/scielo.php?script=sci_arttext\&pid=MSC00000 $00022006000200053 \&$ Ing=en\&nrm=abn>. Acesso em: 12 set. 2017.

EMPRESA BRASILEIRA DE PESQUISA AGROPECUÁRIA - EMBRAPA. Maiores Produtores e Exportadores de Carne Suína do Brasil. Disponível em: $<$ https://www.embrapa.br/suinos-e-aves/cias/estatisticas/suinos/brasil >. Acesso em: 18 maio 2017.

DEGANUTTI, R. et al. Biodigestores rurais: modelo indiano, chinês e batelada. In:

ENCONTRO DE ENERGIA NO MEIO RURAL, 4., 2002, Campinas. Trabalhos... Campinas: UNICAMP; SBEA, 2002.

ENDNOTE. Disponível em: <http://www.endnote.com>. Acesso em: 14 set. 2017

FONSECA, F. S. T.; ARAÚJO, A. R. A.; HENDGES, T. L. Análise de viabilidade econômica de biodigestores na atividade suinícola na cidade de Balsas-Ma, um estudo de caso. In: 47을 Congresso SOBER-Sociedade Brasileira de Economia, Administração e Sociologia Rural. Porto Alegre. 2009.

FUNDAÇÃO ESTADUAL DE MEIO AMBIENTE - FEAM. Guia técnico ambiental de biogás na agroindústria. Belo Horizonte. Fundação Estadual do Meio Ambiente, Federação das Indústrias do Estado de Minas Gerais, Cooperação Alemã para o Desenvolvimento Sustentável (GIZ), 2015.

FRIEHE, J.; WEILAND, P.; SCHATTAUER, A. Fundamentos da Fermentação Anaeróbia. In: FNR. FACHAGENTUR NACHWACHSENDE ROHSTOFFE (Alemanha) (Org.). Guia Prático do Biogás: Geração e Utilização. 5. ed. Gülzow: FNR, 2009. p. 20-30.

FRITSCH, M.; HARTMEIER, W.; CHANG, J. S. Enhancing hydrogen production of Clostridium butyricum using a column reactor with square-structured ceramic fittings. International Journal of Hydrogen Energy, v. 33 pp. 6549-6557, 2008. crossref

GASPAR, R. M. B. L. Utilização de Biodigestores em pequenas e médias propriedades rurais com ênfase na agregação de valor: um estudo de caso na região de Toledo - Pr. 2003. 106 f. Dissertação (Mestrado em Engenharia de Produção) - Programa de Pós-Graduação em Engenharia de Produção. Universidade Federal de Santa Catarina. Florianópolis, 2003. 
HUYSMAN, C. N. Experiences on 18 farms with pig on deep litter. In: Voermans, J.A.M. (ed.). Workshop Deep Litter Systems for Pig Farming. Proceedings... Rosmalen-Netherlands: Research Institute of Pig Husbandry, 1992. p.1-7.

LESSCHEN, J. P. et al. Greenhouse gas emission profiles of European livestock sectors. Animal Feed Science and Technology, v.166-167, p.16-28, jun. 2011. crossref

LIMA, V. M. Manejo produtivo e reprodutivo em granja de suínos. Trabalho de Conclusão de Curso (Bacharel em Zootecnia) - Universidade Federal do Ceará. Fortaleza, 2015.

LUCAS JUNIOR, J.; SOUZA, C. F. Construção e operação de biodigestores. ViçosaMG, CTP, 2009.

MACDONALD, G. K. et al. Agronomic phosphorus imbalances across the world's croplands. Proceedings of the National Academy of Sciences of the United States of America, v.108, n.7, p. 3086-3091, fev. 2011. crossref

MACHADO, G. B. Biodigestor da Cooperativa agrícola Gottingen. 2015. Disponível em: < http://www.portaldobiogas.com/biodigestor-da-cooperativaagricolade-gottingen/>. Acesso em 12 set. 2017.

MARTELLI, L. F. A. Avaliação quantitativa e qualitativa da matéria orgânica de solo sob a aplicação de efluente de esgoto tratado em biodigestor anaeróbico. 2011. 119 f. Dissertação (Mestrado Química) - Instituto de Química de São Carlos. Universidade de São Paulo. São Carlos, 2011.

NEVES, V. L. V. Construção de biodigestor para produção de biogás a partir da fermentação de esterco bovino. Faculdade de Tecnologia de Araçatuba. Curso de Tecnologias de Biocombustíveis. Araçatuba, 2010.

OLIVEIRA JÚNIOR, F. A. de. O ensino não formal da diminuição da carga poluidora de dejetos animais a partir da produção de biogás e biofertilizante em pequenas propriedades rurais / Frederico Alvarenga de Oliveira Júnior. Belo Horizonte, 2013.

OLIVEIRA, P. A.; NUNES, M. A. Sustentabilidade ambiental da suinocultura. Concórdia: Embrapa. 2006. Disponível em:

<http://www.cnpsa.embrapa.br/sgc/sgc_publicacoes/anais0205_oliveira.pdf>. Acesso em: 14 set. 2017. 
RICARDO, C. M. Avaliação econômica de biodigestor de fluxo tubular, com sistema de recirculação, no tratamento de dejetos de suínos. 2012. Dissertação (Mestrado em Engenharia Agrícola) - Universidade Federal de Lavras. Lavras, 2012.

ROHSTOFFE, F. N. Guia Prático do Biogás: Geração e Utilização. Ministério da Nutrição, Agricultura e Defesa do Consumidor da Alemanha, 2010.

SEGAT, J. C. et al. Ecotoxicological evaluation of swine manure disposal on tropical soils in Brazil. Ecotoxicology and environmental safety, v. 122, p. 91-97, 2015. crossref

SILVA, C. B. Abordagem teórica do processo de geração de biometano a partir de resíduos agroindustriais. 2017. Dissertação (Mestrado em Engenharia de Produção) - Universidade Tecnológica Federal do Paraná, Ponta Grossa, 2017.

SIMONI, A. Allevamento di suini stalletti con lettiera permanente prime prove sperimentali. Revista di suinocultura, v.4, p.125-131, 1992.

SOPHA, M. B. et al. Using Systems Engineering to Create a Framework for Evaluating Industrial Symbiosis Options. Systems Engineering, v. 13, n. 02, jun. 2013.

THOMAS, D. G. et al. Utilization Du Biogaz Dans Les Moteurs Thermiques, Informations Chimie, 283, 147-149, Paris, France, 1987.

WEILAND, P. Biogas Production: Current State and perspectives. Applied Microbiology and Biotechnology, [s.I.], v. 85, n.4, p.849-860, 24 set. 2009.

ZHENG, Y. et al. Anaerobic digestion of saline creeping wild ryegrass for biogas production and pretreatment of particleboard material. Bioresource Technology, v. 100 , n. 4, p. 1582-1588, 2009. crossref 
Recebido: 21 set. 2017

Aprovado: 05 dez. 2017

DOI: 10.3895/gi.v13n3.7091

Como citar:

OLIVEIRA, L. G.; SOUZA, J. T.; FRANCISCO, A.C. Tratamento de dejetos suínos: oportunidades de

conversão em energia. R. Gest. Industr., Ponta Grossa, v. 13, n. 3, p. 22-36, set./nov. 2017. Disponível em:

<https://periodicos.utfpr.edu.br/rgi $>$. Acesso em: XXX

Correspondência:

Leandro Gasparello de Oliveira

Av. Monteiro Lobato, s/n - Jardim Carvalho, Ponta Grossa, Paraná, Brasil.

Direito autoral: Este artigo está licenciado sob os termos da Licença Creative Commons-Atribuição 4.0

Internacional.

(c) (1) 